\title{
Bevel Tip Deformation in New and Used Dental Needles
}

\author{
César Gaitán-Fonseca1, Denise Romo-Castillo¹, Bernardino Cerda-Cristerna², \\ David Masuoka1* ${ }^{*}$, Amaury Pozos-Guillén ${ }^{2}$ \\ ${ }^{1}$ Stomatology Department, Aguascalientes University, Aguascalientes City, México \\ ${ }^{2}$ Basic Sciences Laboratory, Faculty of Dentistry, San Luis Potosi University, San Luis Potosí, México \\ Email: ${ }^{*}$ david.masuoka@gmail.com, ${ }^{*}$ dmasuoka@correo.uaa.mx
}

Received 11 November 2014; accepted 4 December 2014; published 14 January 2015

Copyright (C) 2015 by authors and Scientific Research Publishing Inc.

This work is licensed under the Creative Commons Attribution International License (CC BY). http://creativecommons.org/licenses/by/4.0/

c) (i) Open Access

\begin{abstract}
Objectives: To evaluate quantitatively deformation of the angle of the horizontal plane of the bevel tip in new dental needles and in dental needles used in clinical procedures. Material and Methods: A cross-sectional study was performed with 360 dental needles from four different manufacturers. The needles were divided into four groups (90 per group): Group 1, Monoject ${ }^{\circledR}$; Group 2, DLP ${ }^{\circledR}$; Group 3, Badiject, and Group 4, Zeyco. The new and used needles were evaluated by scanning electron microscopy to evaluate quantitatively the deformation on the bevel. Results: All groups showed a significantly statistical difference between new needles and needles used for one or two injections ( $\mathrm{P}<\mathbf{0 . 0 5}$ ), except for those of Group 4, which exhibited no statistical difference. Conclusion: All dental needles used demonstrated tip deformation after their use, but in addition, dental needles without clinical use also showed deformation.
\end{abstract}

\section{Keywords}

Bevel Tip, Deformation, Dentistry, Needles

\section{Introduction}

Injection of local anesthetic is the principal method for preventing pain in dental clinical procedures. The anesthesia is usually effective, but failure of technique is possible due to different causes, including that low effectiveness of the anesthetic might occur due to treatment type, anatomic variations, and pathological and psychological causes [1]. When failure occurs, the most common course of action comprises infiltrating a second dose of the anesthetic [1] [2], which usually takes place without replacement of the needle. However, performing the

*Corresponding author.

How to cite this paper: Gaitán-Fonseca, C., Romo-Castillo, D., Cerda-Cristerna, B., Masuoka, D. and Pozos-Guillén, A. (2015) Bevel Tip Deformation in New and Used Dental Needles. Microscopy Research, 3, 1-5.

http://dx.doi.org/10.4236/mr.2015.31001 
repetition of injection with the same needle can cause pain or tissue damage associated with deformation of the tip of the needle's bevel [3].

Injection with dental needle can produce nerve and muscle damage. Hillerup et al. [4] reported 17\% injury due to iatrogenic causes to the trigeminal nerve after injection. Paresthesia subsequent to injection is relevant to the mechanical action and curved bevel of the dental needle [5]. The curved or hooked bevel may deviate from the horizontal plane or inward, with the former more harmful for tissues [6]. The bevel fold is relevant to the anesthetic technique because this depends on the position and contact of the needle tip with bone [6] [7]. But a curved/hooked bevel is also employed in anesthesia techniques with no bone contact. Rout et al. [7] observed deformation in 13 of 59 needles employed in anesthetic techniques without contact with bone. Almendros et al. [8] found a distortion in the bevel of needles employed in anesthetic techniques without expected bone contact; bevel deformation was not associated with numbers of contacts with bone. Deformation is related with several factors, such as operator variations, force applied, and bevel characteristics [8] [9]; in addition, poor-quality needles can present a deformation in manufacture without clinical use [10].

International Organization for Standardization (ISO) 7864 describes the suggested features for sterile hypodermic needles including bevel properties [11], and ISO 7885 regulates dental needles [12]. This document describes that butt-end angle comprises an inclined bevel plane of bevel that, at its junction with the tip of the horizontal plane, should range between $15^{\circ}$ and $55^{\circ}$ [13]. ISO 7885 refers that the horizontal-plane angle should be pointed and free of cuts on the edge, hooks, rugosity, or any other defects; However, ISO 7885 omits any statement on a new dental needle requiring a horizontal-plane angle of $0^{\circ}$. Evaluation of the horizontal plane of new, and also used, dental needles is of interest.

The aim of this study was to evaluate quantitatively the angle of the horizontal plane of the bevel tip in new dental needles and also in dental needles used in clinical procedures.

\section{Material and Methods}

A cross-sectional study was conducted according to the Declaration of Helsinki; written informed consent was explained and obtained from of each patient. A total of 240 patients were subjected to local anesthesia of the inferior alveolar nerve or infiltrative as a prior step to conventional dental treatment (surgical or operative).

Evaluations were performed in 360 30-gauge dental needles $21 \mathrm{~mm}$ in length. The dental needles were from different manufacturers and were divided into four groups of 90 samples each as follows: Group 1 (Monoject $^{\circledR}$, 30 short-gauge short, triple-bevel, stainless steel, with polypropylene connector and aluminum insert (Kendall, Covidien, USA); Group 2 (DLP ${ }^{\circledR}, 30$ short-gauge, stainless steel AISI 304 and medical-grade plastic $100 \%$ simple (Corporativo DL, S.A. de C.V, Mexico)); Group 3 (Badiject, 30 short-gauge, Laboratoire A.T.O. ZIZINE, France), and Group 4 (Zeyco, 30 short-gauge, stainless steel with polypropylene cap and triple bevel tip (GRUPO ZEYCO, Mexico)).

The dental needles were randomly distributed for use by undergraduate dentistry students. In addition to universal recommendations on the handling of the dental needle, we indicated to the students that close attention should be paid to the manipulation of the dental needles in order to avoid distortion of the needle tip. In the four groups, the dental needles were distributed as follows: 30 needles were employed for one infiltration; 30 needles for two clinical infiltrations per needle, and 30 needles without clinical use as the control group. The dental needles were collected and covered with special care to avoid their deformation. Care was also taken in the use of the samples for the following procedure.

All of the collected samples were first observed with a stereoscopic microscope (Labomed CZM4, USA). The samples were placed horizontally with the bevel pointing to right side in order to observe the active tip laterally. Bevel deformation was classified as internal deformation (up) or external deformation (down), respectively, to the horizontal plane. The tip of all samples was imaged with a digital camera (Digistar) and deformation on the needle tip was measured with an MB-Ruler digital conveyor ${ }^{\odot}$ (Markus Bader-MB-Software Solutions, Germany). Then, the samples were examined with scanning electronic microscopy (JEOL JSM-5900, Tokyo, Japan) at $900 \times$ magnification to assess bevel deformation. The values were analyzed by Graph Pad Instat 3.06 and Graph Pad Prism 5.01 for Windows software (Graph Pad Software, San Diego, CA, USA). Kruskal-Wallis and Mann-Whitney $U$ tests were utilized to find statistical significance differences, and $\mathrm{P}$ was set at $<0.05$.

\section{Results}

Table 1 depicts means, standard deviations (SD), and ranges for bevel deformation in degrees for all groups in 
Table 1. Deformation of the dental needle.

\begin{tabular}{ccccc}
\hline & Group 1 & Group 2 & Group 3 & Group 4 \\
\hline \multirow{4}{*}{ New } & $-5.31 \pm 6.79$ & Mean \pm SD (range) \\
1 Infiltration & $(-16.9-0.00)$ & $-9.12 \pm 15.85$ & $-4.06 \pm 7.04$ & $-4.69 \pm 6.19$ \\
& $-7.21 \pm 23.91$ & $(-51.06-49.27)$ & $(-20.73-7.02)$ & $(-18.10-0.00)$ \\
2 Infiltrations & $(-53.08-59.63)$ & $31.34 \pm 51.60$ & $12.76 \pm 34.81$ & $0.63 \pm 40.35$ \\
P value & $3.89 \pm 22.26$ & $(-74.05-107.11)$ & $(-74.81-115.57)$ & $(-76.34-74.96)$ \\
& $(-31.58-88.33)$ & $3.26 \pm 46.79$ & $-2.15 \pm 31.34$ & $5.12 \pm 45.20$ \\
& 0.0518 & $(-73.05-94.46)$ & $(-71.76-49.82)$ & $(-63.12-106.32)$ \\
\end{tabular}

$\mathrm{SD}=$ Standard deviation; Deformation $(-)=$ deformation of bevel up to horizontal plane; Deformation $(+)=$ deformation of bevel down to horizontal plane.

needles including new, one, and two infiltrations. Statistically significant differences were observed among bevel deformations in Groups 1, 2 and $3(\mathrm{P}<0.05)$. However, a statistically significant difference was not observed in Group $4(\mathrm{P}>0.05)$. Figure 1 illustrates representative views of the different dental needles observed at $900 \times$ magnification. These images showed bevel deformation in all groups included in the study.

\section{Discussion}

Studies have investigated dental needles and their characteristics, such as penetration forces, bevel deformation, pain sensation, needle breakage, and others [9]. In the present study, we quantitatively evaluated bevel deformation in new dental needles and in dental needles employed in different techniques of local anesthetics. The bevel tip may present a hook-type with internal or external direction in relation to the horizontal plane of the dental needle. This deformation might produce damage in tissues, nerves, and failure in anesthesia [14] [15]. Deformation occurs because of the force applied on the dental needle during the injection, several needle uses, operator variations, and when the tip of the needle contacts maxillary or mandibular bone during the anesthetic technique [1] [9].

Bevel deformation is related with needle deflection and is defined as needle curvature or deviation as a result of tissue resistance during insertion. Some factors that exert an influence on deflection comprise metal alloy, amount of silicon, gauge, length, and bevel orientation [16]. Almendros et al. [8] and Delgado-Molina et al. [16] found no statistically significant differences in terms of needle deflection and internal gauge, the anesthetic technique used, the clinician performing the procedure, or the procedure itself. However, these authors consider that deflection was affected by operator performance and not by the internal gauge used. Other important factors to take into consideration in bevel deformation include anesthetic technique, needle deflection, anatomic structures, operator experience, operator performance, and the manufacture of the dental needle material [1] [5]-[8]. Kusin et al. [17] evaluated needle-tip deformation with regular bevel and surgical edge after periodontal anesthesia. They found that in all cases of periodontal anesthesia, needle-tip deformation presents bends ranging from $15^{\circ}-180^{\circ}$ in single and multiple uses.

We observed negative deformation (bevel up with respect to the horizontal plane) and positive deformation (bevel down with respect to the horizontal plane). In the case of new needle tips, when these presented deformation, the range was between $-4.06^{\circ}$ and $-9.12^{\circ}$; in one use, the range was between $-7.21^{\circ}$ and $31.34^{\circ}$, and for a second use, deformation ranged between $-2.15^{\circ}$ and $5^{\circ}-12^{\circ}$. Although Group 4 did not show statistical significance, it exhibited the presence of deformation. All groups demonstrated needle-tip deformation that was independent of the manufacturer and the anesthetic technique. The United States Air Force (USAF) Dental Evaluation \& Consultation Service evaluated 27-gauge Needle Covers (Sheaths) More Prone to Puncture; they reported that Henry Schein needle sheaths displayed a mean deformation resistance force of $0.74 \pm 0.05$ Megapascals (MPa), while the Dentsply product had a mean force of $0.82 \pm 0.04 \mathrm{MPa}$ [18]. In the case of new dental needles presenting deformation, these did not comply with ISO 7885, which indicates that the bevel should be pointed, free of cuts on the edge, and without hooks, rugosity, or other defects [12]. This is a problem because defects were microscopic in size and were not evident to the operator. A strategy for detecting these bevel deformations is to pass the dental needle through gauze. In the SEM evaluation, we present representative images of the dental needles collected, independent of the anesthetic technique employed. We observed a deformation on the tip of new dental needles, or after one and two infiltrations. Rout et al. [7] evaluated 27-gauge local 

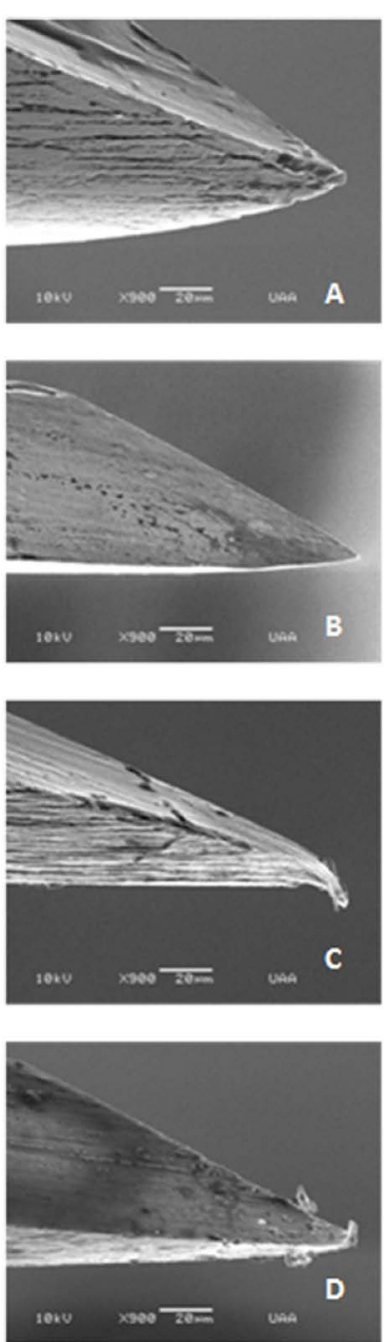
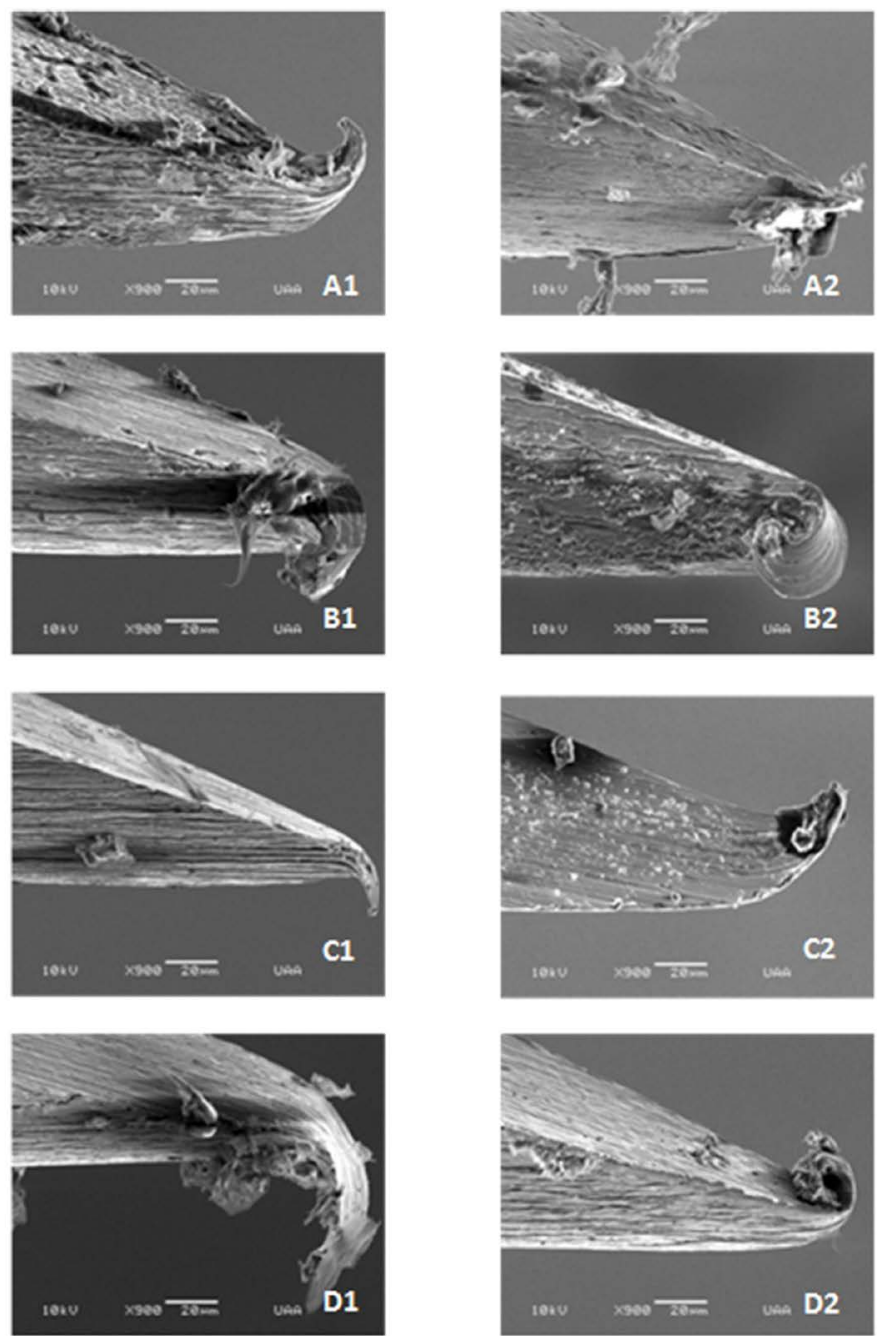

Figure 1. Images at SEM of different dental needles. Images A, B, C, and D illustrate all groups of new dental needles. Images A1, B1, C1, and D1 depict bevel deformation after one infiltration. Images A2, B2, C2, and D2 showed bevel deformation after two infiltrations.

anesthetic needles employed in four commonly performed local anesthetic-injection techniques. The needles were examined for needle-tip damage under scanning electron microscopy. Bone was contacted in 75 (59\%) instances, and of these, 73 (97.3\%) these exhibited needle-tip deformity. Of the four techniques utilized, bone contact was most common with inferior alveolar nerve block, occurring in $88 \%$ of instances. For future studies, it is recommendable to evaluate correlation among force, design, and tip deformation in order to make recommendations for the manufacture of dental needles. The findings of this study demonstrated that all new dental needles showed tip deformation and used needles additionally showed stronger deformation. These results should be considered to avoid tissue damage in different local anesthetic techniques in dentistry.

\section{Conclusions}

Efficiency of dental needles depends on the shape and hardness of the tip, for this reason the change of the needle is important when performing several repetition of injection.

All dental needles used demonstrated tip deformation after their use, but in addition, dental needles without clinical use also showed deformation, probable due to handling during manufacturing and packaging. However it often goes unnoticed by the clinician.

Future investigations should be directed at the study and comparison of the composition of the needles. 


\section{Conflict of Interest}

The authors declare they have not conflict of interests.

\section{References}

[1] Meechan, J.G. (2005) Why Does Local Anaesthesia Not Work Everytime? Dent Update, 32, 66-68, 70-72.

[2] Nusstein, J.M., Reader, A. and Drum, M. (2010) Local Anesthesia Strategies for the Patient with a "Hot” Tooth. Dental Clinics of North America, 54, 237-247. http://dx.doi.org/10.1016/j.cden.2009.12.003

[3] Ethunandan, M., Tran, A.L., Anand, R., Bowden, J., Seal, M.T. and Brennan, P.A. (2007) Needle Breakage Following Inferior Alveolar Nerve Block: Implications and Management. British Dental Journal, 202, 395-397. http://dx.doi.org/10.1038/bdj.2007.272

[4] Hillerup, S. (2007) Iatrogenic Injury to Oral Branches of the Trigeminal Nerve: Records of 449 Cases. Clinical Oral Investigations, 11, 133-142. http://dx.doi.org/10.1007/s00784-006-0089-5

[5] Crean, S.J. and Powis, A. (1999) Neurological Complications of Local Anaesthetics in Dentistry. Dent Update, 26, 344-349.

[6] Stacy, G.C. and Hajjar, G. (1994) Barbed Needle and Inexplicable Paresthesias and Trismus after Dental Regional Anesthesia. Oral Surgery, Oral Medicine, Oral Pathology, Oral Radiology, 77, 585-588. http://dx.doi.org/10.1016/0030-4220(94)90315-8

[7] Rout, P.G., Saksena, A. and Fisher, S.E. (2003) An Investigation of the Effect on 27-Gauge Needle Tips Following a Single Local Anaesthetic Injection. Dent Update, 30, 370-374.

[8] Almendros-Marques, N.A., Delgado-Molina, E., Tamarit-Borras, M., Berini-Aytes, L. and Gay-Escoda, C. (2007) Comparison of Two Needle Models in Terms of Bevel Deformation during Truncal Block of the Inferior Alveolar Nerve. Medicina Oral, Patología Oral y Cirugía Bucal, 12, E317-E322.

[9] Steele, A.C., German, M.J., Hass, J., Lambert, G. and Meechan, J.G. (2013) An in Vitro Investigation of the Effect of Bevel Design on the Penetration and Withdrawal Forces of Dental Needles. Journal of Dentistry, 41, 164-169. http://dx.doi.org/10.1016/j.jdent.2012.10.016

[10] Trombelli, L., Nonato, M., Ferrari-Carpino, C., Orsini, L. and Saletti, C. (1990) Needles in Dental Practice. Clinical Evaluation and Experiments on Deformation and Siliconization. Journal of Dental Anesthesia, 19, 7-14.

[11] Standardization IOf. ISO 7864:1993 (1993) Sterile Hypodermic Needles for Sinle Use. International Organization for Standardization, Geneva.

[12] Standardization IOf. ISO 7885:2010 (2010) Dentistry-Sterile Injection Needles for Single Use. International Organization for Standardization, Geneva.

[13] Pejcic, A. and Mirkovic, D. (2011) Anti-Inflammatory Effect of Low Level Laser Treatment on Chronic Periodontitis. Medical Laser Application, 26, 27-34. http://dx.doi.org/10.1016/j.mla.2010.04.004

[14] Steinkruger, G., Nusstein, J., Reader, A., Beck, M. and Weaver, J. (2006) The Significance of Needle Bevel Orientation in Achieving a Successful Inferior Alveolar Nerve Block. Journal of the American Dental Association, 137, 1685-1691. http://dx.doi.org/10.14219/jada.archive.2006.0114

[15] Misra, S., Reed, K.B., Douglas, A.S., Ramesh, K.T. and Okamura, A.M. (2008) Needle-Tissue Interaction Forces for Bevel-Tip Steerable Needles. Proceedings of the IEEE RAS \& EMBS International Conference on Biomedical Robotics and Biomechatronics, 19, 224-231.

[16] Delgado-Molina, E., Tamarit-Borras, M., Berini-Aytes, L. and Gay-Escoda, C. (2009) Comparative Study of Two Needle Models in Terms of Deflection during Inferior Alveolar Nerve Block. Medicina Oral Patologia Oral y Cirugia Bucal, 14, e440-e444.

[17] Kuzin, A.V., Ereskina, Y.V. and Kurtyshov, A. (2014) Needle Tip Deformation after PDL and Intraseptal Dental Local Anesthesia. Journal of Head \& Neck Physicians and Surgeons, 2, 48-52.

[18] USAF Dental Evaluation \& Consultation Service. Henry Schein Inc. (2011) 27 Gauge Needle Covers (Sheaths) More Prone to Puncture (1/07). 
Scientific Research Publishing (SCIRP) is one of the largest Open Access journal publishers. It is currently publishing more than 200 open access, online, peer-reviewed journals covering a wide range of academic disciplines. SCIRP serves the worldwide academic communities and contributes to the progress and application of science with its publication.

Other selected journals from SCIRP are listed as below. Submit your manuscript to us via either submit@scirp.org or Online Submission Portal.
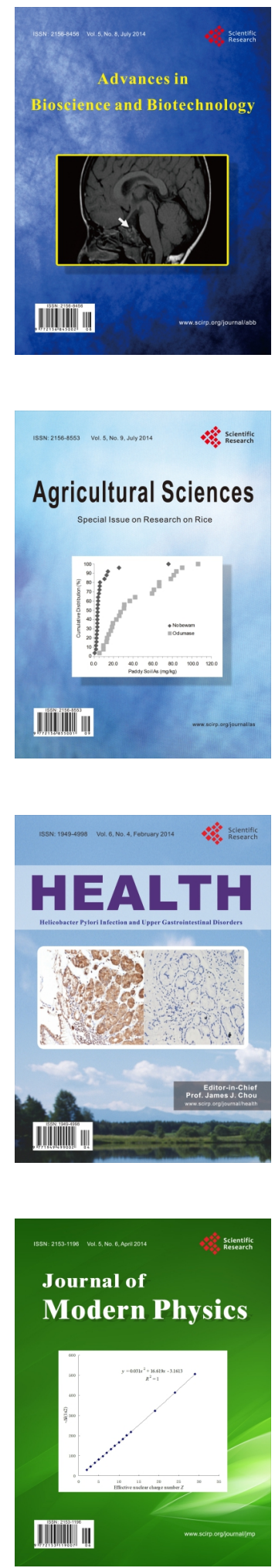
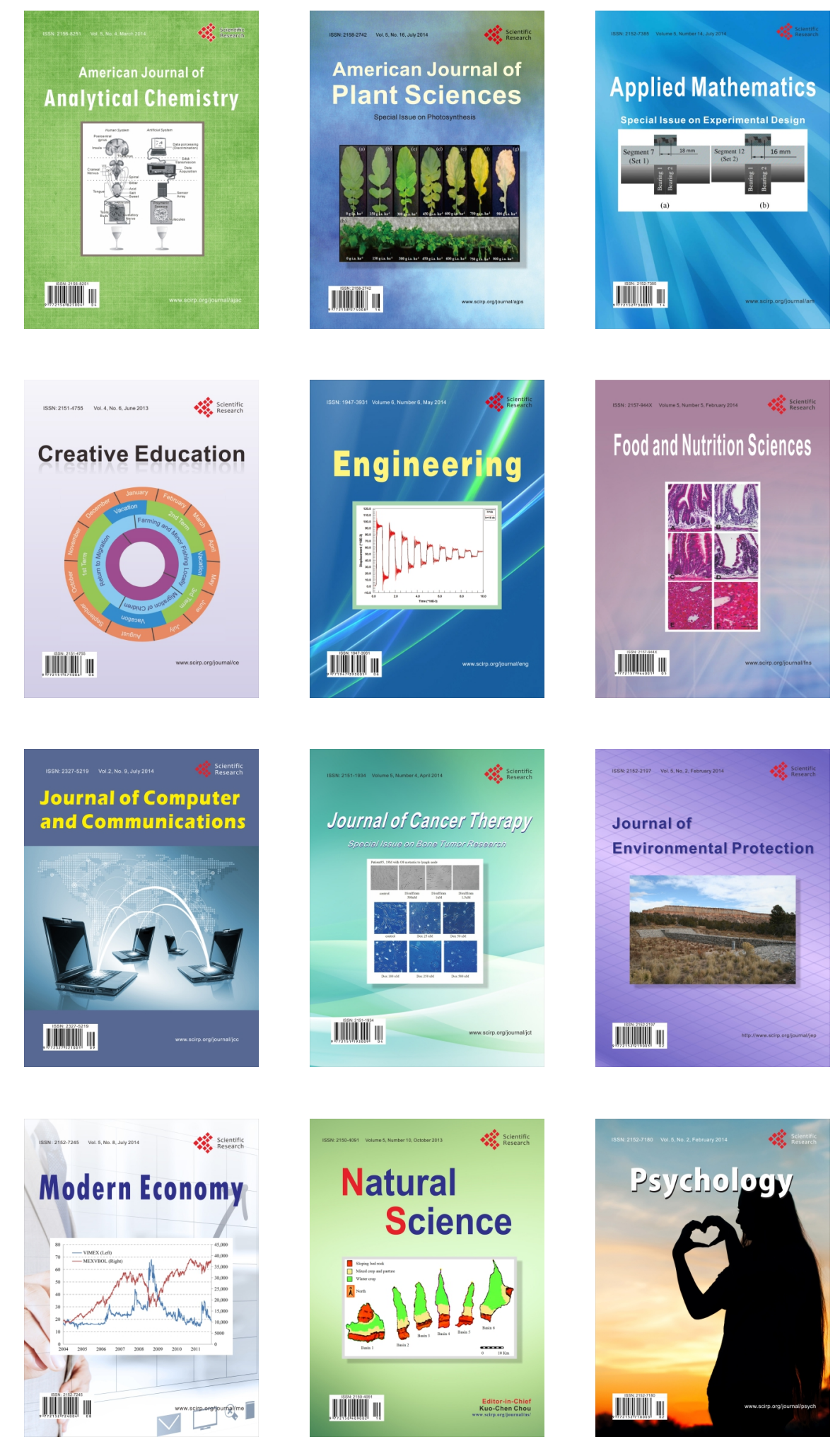